\title{
Value-adding to health professional student placement experiences: Enhancing work readiness and employability through a rural community engagement program
}

\author{
Karin Fisher ${ }^{1}$, Tony Smith ${ }^{1}$, Leanne Brown ${ }^{1}$, Luke Wakely ${ }^{1}$, Alex Little ${ }^{1}$, Katrina Wakely ${ }^{1}$, \\ Judith Hudson ${ }^{2}$ and Kelly Squires ${ }^{1}$ \\ karin.fisher@newcastle.edu.au; tony.smith@newcastle.edu.au; \\ leanne.brown@newcastle.edu.au; luke.wakely@newcastle.edu.au; \\ alexandra.little@newcastle.edu.au; katrina.wakely@newcastle.edu.au; \\ nicky.hudson@newcastle.edu.au; kelly.squires@newcastle.edu.au \\ ${ }^{1}$ University of Newcastle Department of Rural Health \\ ${ }^{2}$ University of Newcastle, School of Medicine and Public Health
}

\begin{abstract}
Enriching health professional students' placement experiences through targeted community engagement has the potential to help develop their preparedness to provide healthcare to the broader community. In 2011 the University of Newcastle Department of Rural Health (UONDRH) embarked on a program of multidisciplinary community engagement which consisted of short, extracurricular community-engaged learning experiences integrated with the students' professional placements. The aim of this study was to investigate whether the program was adding to the students' rural health placement experiences based on perceptions of both the students themselves and UONDRH staff.

A mixed methods approach used a student survey $(n=96)$, which included both closed and open-ended questions, and semi-structured interviews with staff members involved in delivery of the community engagement program $(n=15)$. Data were explored together for intersections and commonalities. The overarching key concept was 'Enhancing Work Readiness and Employability'. Both student and staff perceived that students' participation in community engagement improved their employment prospects. Three themes emerged from the data, which underpinned and supported the key concept. These were: 'Expanding professional practice capabilities'; 'Building confidence and showing motivation', and 'Better understanding the nature of rural practice'.

The results of this study provide support to the notion that there was value for students in this form of short-term, community engagement activities, many of which could be readily integrated into existing health professional education programs with considerable benefits. It would also lend itself to other non-health professional programs, such as law, journalism or business studies, as a means of broadening the students' perspectives beyond the limits of their own professional horizons.
\end{abstract}

Keywords: Graduate attributes; rural health; undergraduate education; workforce; work integrated learning; professional placements 


\section{Introduction}

Changes occurring in higher education, such as new technology, globalisation, economic and industrial restructuring, along with the need to improve productivity, place pressure on universities to respond, adjust to changes and produce capable, work-ready graduates (Universities Australia, 2015). Industry demands and employer expectations require graduates to have a broad skill set that will enable them to integrate readily into the workforce and be able to solve complex problems (Millican \& Bourner, 2011). These broad skills valued by employers include resilience, teamwork, communication, personal and social qualities, and self-management (Caballero \& Walker, 2010; Caballero, Walker, \& Fuller-Tyszkiewicz., 2011; Hager \& Holland, 2006; Messum, Wilkes, \& Jackson, 2015; Walker et al., 2013). Generally students themselves also want to develop such skills (Thompson, Clark, Walker, \& Whyatt, 2013) and thus enhance their employment prospects (Qenani, MacDougall, \& Sexton, 2014).

To address these expectations, there is an argument for an increasing use of communityengaged models of learning, increasing students' social consciousness, adding richness to educational experiences (Furze, Black, Peck, \& Jensen, 2011) and improving graduate employment potential. It is also important to concurrently address particular community needs (Butin, 2010). Universities can develop a range of collaborative community partnerships and support a diversity of student experiences beyond traditional educational models and modes of delivery (Baum, 2000; Boelen \& Woollard, 2009; Bringle \& Hatcher, 2002) that includes community engaged programs.

The term 'community engagement' is a contested notion with multiple interpretations. It has been argued elsewhere that there is no agreed definition (Moore, McDonald, McHugh-Dillon, \& West, 2016) and that it is a free-floating philosophy (Butin, 2010, p.133), which is adaptable along a continuum. There are a range of different definitions such as work-integrated models (Universities Australia, 2015) service learning models (Stanton, Giles Jr, \& Cruz, 1999) and experiential learning models (Kolb, 2014). Inherent within the different definitions, theories and applications however, is agreement that there are a number of student benefits for personal and academic growth (Deeley, 2014; Hébert \& Hauf, 2015), collaborative practice (Croker, Brown, Little, \& Crowley, 2016) and transformative learning (Caspersz \& Olaru, 2017; Prout, Lin, Nattabi, \& Green, 2014). Community benefits are less articulated and include co-produced outcomes where partnerships are initiated by communities to address areas of need (Jones, McAllister, \& Lyle, 2016a).

Many of the studies fall into two types of community engagement: curriculum-based and noncurriculum based. Curriculum-based programs, namely service learning, is a form of learning that combines student learning with community service. The program explicitly articulates learning objectives where students participate in an organised service activity that meets community needs and is followed by structured reflection as it relates to course material (Bringle \& Hatcher, 1996). According to Butin (2010) service learning rejects the banking model of education where students are passive recipients who accept deposits of knowledge from teachers (Friere, 1996). By rejecting the banking model, service learning is perceived to be a way to re-engage students in their knowledge quest and civic values (Butin, 2010).

Examples of curriculum-based community engagement focus mainly on social justice and responsibility (Marullo \& Edwards, 2000; Peck, Furze, Black, Flecky, \& Nebel, 2010) and are experiential and transformative (Prout et al., 2014), where others focus on the acquisition of knowledge and skills (Jones, McAllister, \& Lyle, 2015; Rooks \& Rael, 2013) for instance public health (Cashman \& Seifer, 2008). Non-curriculum based programs are generally extracurricular and tend to focus more on 'life-wide learning' (Thompson et al., 2013), and are complementary rather than specific to an undergraduate degree (Clark, Marsden, Whyatt, Thompson, \& Walker, 2015).

Fisher, K., Smith, T., Brown, L., Wakely, L., Little, A., Wakely, K., Hudson, J., \& Squires, K. (2018). Value-adding to health professional student placement experiences: Enhancing work readiness and employability through a rural community engagement program. Journal of Teaching and Learning for Graduate Employability, 9(1), 41-61. 
Hence, promotion of a university-community collaborative model (Eklund, 2014), with reinforcement of mutually beneficial outcomes (Dettwiller, Maroney, \& Brown, 2015) and development of inter-sectoral partnerships (Kirby, Held, Jones, \& Lyle, 2018) are at the forefront of university priorities, responsibilities and strategies. However, although community engagement has potential benefits for all concerned, in particular for students such as enhanced employability, self-efficacy and skill set (Millican \& Bourner, 2011), it is not without challenges and risks (Moore, McDonald, McHugh-Dillon, \& West, 2016; Weerts \& Sandmann, $2008,2010)$. While there are benefits for students, there are challenges and impediments to creating mutually beneficial relationships with the community (Blouin \& Perry, 2009). The valuable role of the community must be acknowledged, individual and organisational voices heard, and the risk of demanding too much of the community, leading to disillusionment and disengagement, avoided (Butin, 2010; Moore et al., 2016).

\section{Background and context}

In order to help broaden the range of students' educational experiences, in 2011 the University of Newcastle Department of Rural Health (UONDRH) began a community engagement program with a suite of activities (Table 1). The UONDRH is funded under the Australian Government's Rural Multidisciplinary Training (RHMT) Program, the primary aim of which is to build future rural health workforce capacity by supporting effective undergraduate student rural placement experiences (Australian Government Department of Health, 2016). The UONDRH is located in the northern New South Wales (NSW) region of Australia. Like other regional, rural and remote areas, both in Australia and internationally, the region experiences health workforce shortages (Humphreys et al., 2008; Joyce \& Wolfe, 2005; Lyle et al., 2007; Wakerman \& Humphreys, 2012), exacerbated by difficulty recruiting and retaining adequate numbers of health professionals (Buykx, Humphreys, Wakerman, \& Pashen, 2010).

Students from the disciplines of Medicine, Nursing, Nutrition and Dietetics, Occupational Therapy, Medical Radiation Science, Diagnostic Radiography, Speech Pathology, Physiotherapy, Pharmacy and Podiatry participate in rural professional practice placements in the region with the support of staff from UONDRH. Placements vary in duration from two weeks to a full academic year, depending on curriculum requirements, the latter including both academic and professional placement weeks. The UONDRH employs academic staff in all of the above disciplines to provide teaching and placement support to students, in collaboration with supervisory staff in the local public and private health service facilities. In addition, the UONDRH employs administrative (or professional) staff members to operationalise and support the community engagement program. Community engagement activities are undertaken by the students either as a formal component of their professional placement or voluntarily as an extracurricular educational activity, depending on the discipline concerned.

Based on an asset approach (Mathie \& Cunningham, 2003) the purpose of the UONDRH community engagement program is to encourage students on professional placements in the region to integrate with the local community, particularly with rural people from low socioeconomic and Indigenous backgrounds. The health outcomes of these groups are generally poorer than for the Australian population as a whole (Australian Institute of Health and Welfare (AlHW), 2014). It is intended, therefore, that through engaging with the community as part of their rural educational experience, students gain a better appreciation of their future potential role in health promotion and disease prevention as graduate health professionals. It is also intended that they become more acutely aware of issues related to healthcare service delivery and access in non-metropolitan communities as there are many characteristics of rural practice that differ from urban-based practice (Furlong, Clews, \& Randall, 2009; Joyce, McDonald, \& Lawlor-Smith, 2016; McGrail, Humphreys, Joyce, Scott, \& Kalb, 2012).

Fisher, K., Smith, T., Brown, L., Wakely, L., Little, A., Wakely, K., Hudson, J., \& Squires, K. (2018). Value-adding to health professional student placement experiences: Enhancing work readiness and employability through a rural community engagement program. Journal of Teaching and Learning for Graduate Employability, 9(1), 41-61. 
Table 1 lists examples of community engagement activities in partnership with the local community that are offered to UONDRH students, the duration and frequency of each and the various partner organisations involved.

\section{Table 1: Examples of the Range of Community Engagement Activities on Offer to University of Newcastle Department of Rural Health (UONDRH) Students}

\begin{tabular}{|c|c|c|}
\hline Partner Organisations & Community Engagement Activity & Duration \& Frequency \\
\hline \multirow[t]{4}{*}{$\begin{array}{l}\text { Local Primary Schools in } \\
\text { the UONDRH region }\end{array}$} & Eat-Well-2-Learn-Well Breakfast Club & $\begin{array}{l}11 / 2 \text { hours, Monday to Friday } \\
\text { in school terms }\end{array}$ \\
\hline & $\begin{array}{l}\text { After School Learning Centres } \\
\text { (2 different schools) }\end{array}$ & $\begin{array}{l}2 \text { hours, } 3 \times \text { per week at one } \\
\text { school and } 2 \times \text { per week at } \\
\text { the other }\end{array}$ \\
\hline & Multicultural Cooking in Schools & 4- 6 hours, $2 \times$ per year \\
\hline & $\begin{array}{l}\text { Isolated Aboriginal Primary School - } \\
\text { Multidisciplinary Health Education Days }\end{array}$ & $\begin{array}{l}1 \text { school day, } 3 \text { or } 4 \times \text { per } \\
\text { year }\end{array}$ \\
\hline
\end{tabular}

Tamworth Family Support Services

Dhiiyaan Early Childhood Playgroups

2 hours, $5 \times$ per year

Biralee MACS

Multifunction Aboriginal Birrelee Early Development Program 2 hours x per year

Children Service

\begin{tabular}{lll}
\hline Tamworth Lands Council & Midnight Basketball & $\begin{array}{l}4 \text { hours, } 1 \text { day each week for } \\
2 \times 8 \text { week tournaments }\end{array}$ \\
\hline $\begin{array}{lll}\text { HealthWISE New } \\
\text { England Northwest }\end{array}$ & $\begin{array}{l}\text { Ag Quip agricultural field days - Health } \\
\text { and Hearing Checks }\end{array}$ & 3 full days once per year \\
\hline
\end{tabular}

Tamworth Aboriginal

Medical Service \& One Deadly Step - Aboriginal Chronic

HealthWISE New

Disease Health Screening

1 full day, $1 \times$ per year

England Northwest

\begin{tabular}{lll}
\hline $\begin{array}{l}\text { Isolated Regional Primary } \\
\text { Schools }\end{array}$ & $\begin{array}{l}\text { Teddy Bear Hospital \& } \\
\text { Bush Kids First Aid Education }\end{array}$ & $\begin{array}{l}1 / 2 \text { to } 1 \text { day, up to } 15 \text { x per } \\
\text { year }\end{array}$ \\
\hline $\begin{array}{l}\text { Primary Schools and } \\
\text { Support Unit }\end{array}$ & Fine Motor Skills Workshops & $\begin{array}{l}2 \text { hours, 1 day per week for } 4 \\
\text { weeks in 3 different schools }\end{array}$ \\
\hline $\begin{array}{l}\text { UONDRH } \\
\text { Secondary Schools }\end{array}$ & Health Careers Forum & $\begin{array}{l}\text { Once per year in two } \\
\text { different regional centres }\end{array}$ \\
\hline
\end{tabular}

*University of Newcastle Department of Rural Health

Most activities range in duration from two hours to one day. With the exception of the Teddy Bear Hospitals and Careers Forums, the activities listed in Table 1 are not planned, implemented or funded by the UONDRH. Rather, the UONDRH community engagement team identifies existing community-based activities where students may become involved (Fisher, Squires, \& Woodley, 2016). They then liaise with the external organisations, negotiate partnership agreements, and resource the UONDRH students' involvement, in collaboration with the relevant academics. For example, Eat-Well-2-Learn-Well Breakfast Clubs existed before the Nutrition and Dietetic students began providing the primary school students, 
parents and teachers with additional information about healthy eating and cooking. Similarly, After School Learning Centres existed before UONDRH students started doing health education activities with the primary school students. The same is true of Midnight Basketball, the Dhiiyaan Early Childhood Playgroups and Birralee Early Development Program; the activities belong to the community, with their own, pre-existing aims and objectives, but the UONDRH students engage by providing complementary, hands-on, health-oriented, practical and educational contributions. Thus, the ownership is vested in the community and should the UONDRH discontinue involvement, the programs and activities would continue, though without the university students' input.

The guiding principle of the partnership agreements is collaboration to support involvement of university students in existing community-based activities. The UONDRH undertakes to coordinate staff and student involvement and provide the necessary resources to conduct, for example, 'information sessions or workshops on health-related topics'. All UONDRH students receive local Indigenous cultural training as part of their professional placement, as a requirement of the RHMT funding agreement. Students must have completed this training before they undertake any community engagement activities. The partner organisations undertake to conduct the activities and communicate opportunities for UONDRH students' involvement. Students attend in multidisciplinary or profession-specific groups, depending on the activity. They are briefed and given any necessary specific preparation by the academic staff and debriefed afterwards about what they gained from the experience and what could have been improved.

Table 2 shows the number of students who completed placements in the region and the number who participated in community engagement activities annually between 2011 and 2016. Some students participated in multiple activities on multiple occasions, with the hours of participation for individual students ranging from two to 65 hours. The program grew rapidly over the first two years to involve more than 150 students a year, with more than 500 occasions of participation.

\section{Table 2: Student Participation in the University of Newcastle Department of Rural Health (UONDRH) Community Engagement Program from 2011 to 2016.}

\begin{tabular}{lrrrrrr}
\hline Measures of student participation & $\mathbf{2 0 1 1}$ & $\mathbf{2 0 1 2}$ & $\mathbf{2 0 1 3}$ & $\mathbf{2 0 1 4}$ & $\mathbf{2 0 1 5}$ & $\mathbf{2 0 1 6}$ \\
\hline Total eligible students on placement & 201 & 161 & 328 & 341 & 320 & 314 \\
Total students that participated & 64 & 89 & 149 & 213 & 184 & 157 \\
Total occasions of student participation & 179 & 257 & 534 & 842 & 973 & 673 \\
Average occasions of participation per student & 2.8 & 2.8 & 3.58 & 3.95 & 5.3 & 4.3 \\
Average hours of participation per student & 7.4 & 10.2 & 10.1 & 9.9 & 14.0 & 11.5 \\
Total student-hours & 474 & 908 & 1,503 & 2,099 & 2,585 & 1,813 \\
\hline
\end{tabular}

\section{Aim of this study}

This study was grounded in a pragmatic approach. Informal evaluation and anecdotal feedback suggested that the students were gaining new skills and finding considerable value in their involvement in the relatively brief community engagement activities. However, it was also recognised that the program consumed considerable financial and human resources and there was a need to conduct more formal, structured evaluation and research to assess the perceived value of the program to UONDRH students and staff. Higgs' (2011) view of practice- 
based education provided an appropriate framework for the community engagement program research.

The aim of this project, therefore, was to investigate the impact of the community engagement program on students' rural health placement experiences from the perspectives of both the students themselves and UONDRH staff members. The findings could then inform executive level decision-making about ongoing sustainability or potential for further development of the UONDRH community engagement program.

\section{Method}

Ethics approval for this mixed methods research was obtained from the University of Newcastle Human Research Ethics Committee. Data was collected from both the UONDRH staff and students involved in the program, thus increasing the validity and reliability of the findings (Vaismoradi, Turunen, \& Bondas, 2013). Students who had participated in the community engagement program were surveyed over the period between 2011, when the program first began, and 2013. However, it was difficult to recruit past students in large numbers as their contact details were not necessarily up-to-date. Pragmatically, because staff were much fewer in number and more easily accessed, it was decided to invite the academic and professional staff involved in the delivery of the program to participate in qualitative, semistructured, in-depth interviews. This had the added benefit of enriching the data.

A representative group of the UONDRH academic staff members created a purpose-designed questionnaire and students were invited by email to participate in the survey between March and May 2014, which was delivered online via SurveyMonkey ${ }^{\circledR}$. A mixture of categorical, closed-ended and open-ended questions gathered information about the students' gender, age and duration of their placement, as well as their perceptions of the objectives of the community engagement program, their level of satisfaction, and their opinions about perceived benefits of and barriers to their participation. Responses to closed-ended survey questions were downloaded into a Microsoft Excel ${ }^{\circledR}$ spreadsheet, imported into SPSS V22 (Lyle Corporation, 2013) and analysed by descriptive statistics. NVivo 10 qualitative data analysis software (QSR International Pty Ltd, 2012) was used to manage the data.

Qualitative interviews with staff members took place in the second semester of 2014 in a quiet location in the workplace, at a time of the participant's choice. The first author (KF), who had no other involvement in delivering the community engagement program, conducted the recruitment, communications and interviews with the participants. The schedule of interview questions is shown in Table 3. Interviews lasted between 30 and 60 minutes, were audiorecorded, with field-notes made immediately after each interview. A professional transcription service with which the UONDRH has a confidentiality agreement produced Microsoft Word ${ }^{\circledR}$ verbatim transcripts of the audio recordings. Accuracy was checked against recordings and participant validation was invited before files were imported into NVivo 10 for analysis.

Because of the differences in question style, data types and perspectives of the two participant groups, the open-ended student survey responses and transcripts of the staff interviews were initially analysed separately. Later data were explored together for intersections and commonalities. Through interpretation common data categories and themes were developed. Two of the authors (KF and $\mathrm{JH}$ ) did further comparative analysis and subsequently all authors validated and agreed upon the themes. 


\section{Table 3: Schedule of Open-ended Questions used for Semi-structured Staff Member Interviews.}

- How are you involved in the community engagement program (CEP)?

- What do you think are the aims and objectives of the CEP?

- What role did you play in the planning of the CEP?

- To what extent were the CEP activities implemented as planned?

- Describe any barriers and enablers that influenced the design and delivery of the CEP.

- How were or are you involved in the implementation of the CEP?

- What are your thoughts on the value of the CEP?

- To what extent can you make changes to the content and delivery of the material?

- What is your opinion of resource allocation for the CEP? (e.g. costs, time, equipment, props)

- Describe what aspects of the CEP are working or not working (e.g. for whom, why/why not?)

- How do you think the CEP could be improved?

- How well do the educational activities match the intended purpose of the CEP?

- Please comment on the students' participation in the CEP.

- What impact, if any, has the CEP had on the students' professional development?

- What impact, if any, has the CEP had on the students' satisfaction with their placement?

\section{Results}

Emails were sent to the 302 students who had been involved in the community engagement program in 2011, 2012 and 2013 inviting them to participate in the survey; however, only 95 $(32 \%)$ responded, reflecting the difficulty of contacting past students. Most respondents (55\%) had participated in community engagement activities in 2013, while 27 per cent of respondents took part in 2012 and 18 per cent in 2011. The duration of the students' placements varied according to the discipline and the course requirements. Most (38\%) had placements of between three and five weeks duration, with 17 per cent having shorter, one or two week placements and 19 per cent having six to twelve week placements. Twenty-six percent of respondents had placements of 12 weeks or more, including 16 students who reported semester-long or year-long UONDRH attachments greater than 18 weeks duration. The sample was predominately female $(82 \%)$, reflecting the gender distribution in the health professions. Nutrition and Dietetics students accounted for 25 per cent of respondents, with Physiotherapy and Occupational Therapy each being 14 per cent and Medicine 16 per cent. The other five disciplines (Nursing, Speech Pathology, Podiatry, Medical Radiation Science and Pharmacy) made up less than 10 per cent each.

Of the 41 staff members invited, 15 consented to be interview informants, including seven non-academic or professional staff members and eight academics. The latter were from the 
disciplines of Nutrition and Dietetics $(n=2)$, Medicine (1), Medical Radiation Science (1), Physiotherapy (1), Occupational Therapy (2) and Speech Pathology (1).

The findings from both the student survey and staff interviews were integrated to inform the development of a diagrammatic representation of the thematic relationships (Figure 1). A detailed explanation of the diagram follows, with reference to the survey data and illustrative quotations from both the students and staff members. Student quotations are coded by gender, discipline and the year of participation. Given the small number from each discipline, due to confidentiality, the specific discipline of academic staff members is not given against their quotations. Both students and staff members have been allocated a unique, two-digit identification number (ID\#) to differentiate one informant from another. Embedded within the diagrammatic representation is Higgs (2011) practice based framework. In particular, her focus on the social practice dimensions and the key pedagogical practices of independent workplace learning and experience and blended learning.

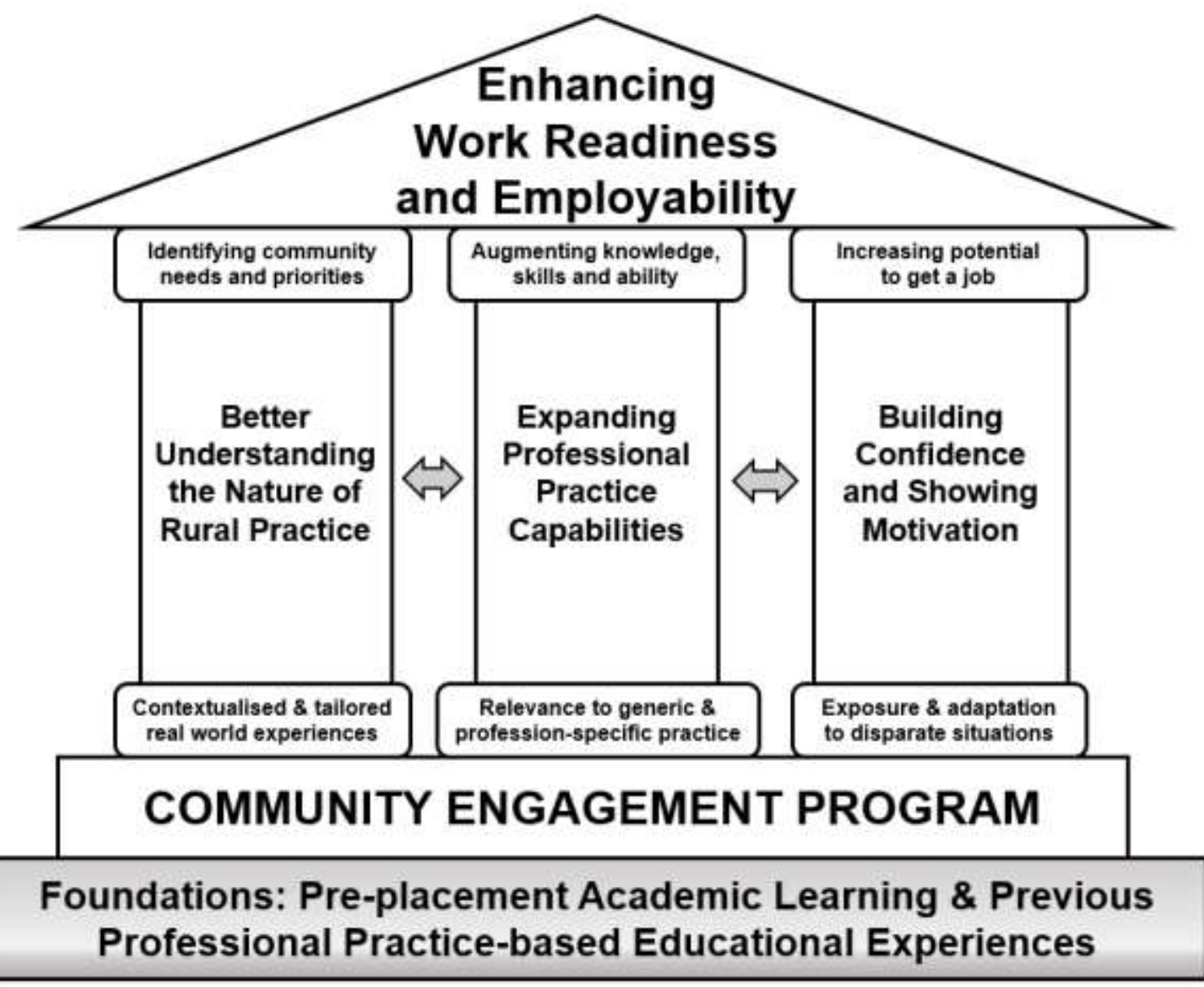

Figure 1: A Diagrammatic Representation of the Thematic Relationships of 'Enhancing Work-readiness and Employability' of Health Professional Students through the University of Newcastle Department of Rural Health Community Engagement Program.

It was perceived that the community engagement program strengthens and builds on the students' pre-existing capabilities. The students who come to the UONDRH on both shortterm or long-term professional placements and extended attachments are already in the process of developing both profession-specific and generic health professional knowledge, 
skills and abilities. That is, the students arrive already equipped to take part in professional placements or attachments, as well as in community engagement, though the latter is less familiar to them than their core professional roles. The students pre-existing capabilities are represented in the model in Figure 1 as the foundation layer of their 'Pre-placement Academic Learning and Previous Practice-based Educational Experiences', upon which the 'Community Engagement Program' rests and without which the program would not be possible. This was represented in the data where staff members made observations about pre-existing knowledge such as the following:

... obviously our students have almost finished their degree so they have got a very strong and large amount of clinical knowledge, ... So, if they're asked a question about something, they have got an opportunity to share their knowledge and look like an expert. (Academic Staff Member, ID\#90)

They actually get to consolidate, so if they're developing education workshops, they're actually applying their knowledge, so they're actually getting a context where they can try things out. They can use their knowledge and the things that they've learned and be able to communicate that. (Professional Staff Member, ID\#82)

Another of the academic staff members drew a distinction between the students using preexisting 'propositional' knowledge, as opposed to the broader, 'non-propositional' knowledge, which it was perceived the students gained through community engagement:

\section{... they often come on placement and they have good theoretical or propositional knowledge and this - if I'm getting those terms right - but they often have really poor life knowledge. I think that's the non-propositional knowledge and so I think that's the key part for me in terms of what they get out of it. (Academic Staff Member, ID\#80)}

In Figure 1, the experiences and potential value and benefits are represented by the three emergent themes, shown as the pillars: 'Expanding Professional Practice Capabilities'; and 'Building Confidence and Showing Motivation' and 'Better Understanding the Nature of Rural Practice'. A description of each theme is given below. Themes are not mutually exclusive but relate to each other horizontally, as indicated by the double-headed broad arrows in Figure 1. Of equal importance, all three 'theme pillars' provide support for the overarching key concept, 'Enhancing Work-Readiness and Employability', represented by the large, triangular 'capstone'. Strategies applied are shown as the foot of each theme pillar and the potential benefits that support the key concept are shown at the head of the pillars.

\section{Expanding professional practice capabilities}

Many of the students volunteered to participate in the community engagement program because it was applicable to their professional practice (44\%). Therefore, the central of the three theme pillars, 'Expanding Professional Practice Capabilities', relates to how the students were able to apply both profession-specific and generic skills in a different context, outside their usual professional placement environment. Students identified that factors limiting their participation in the community engagement program included time constraints $(33 \%)$, scheduling difficulties and conflicting obligations of their other academic commitments $29 \%$ ). About half $(47 \%)$ of the students 'strongly agreed' that they obtained valuable professional experience and $65 \%$ 'agreed' or 'strongly agreed' that it led to changes in their professional practice. Students reported improved ability to communicate $(70 \%)$ and engage with those from vulnerable groups (62\%), such as Aboriginal people, thus contributing to the perceived benefit of 'Augmenting their knowledge, skills and abilities'. Both the professional and academic staff members worked to intentionally develop learning opportunities that would 
benefit the students' future practice and broaden their professional skills, as illustrated in the following quotations:

... that propositional learning experience and the extra teaching and learning. ... They use their natural skills, with feedback they can focus on new skills they need to develop. (Academic Staff Member, ID\#84)

... with the community engagement project it's more probably, like the soft skills, I guess, like their communication style and how they build rapport in that environment. Part of their assessment might also be looking at their ability to interact across agencies. So, it's probably a whole bundle of skills the students are using when they get involved with the after-school learning centre ... (Academic Staff Member, ID\#90)

Students also recognised the opportunity to practice their communication skills as seen in the following comments:

An opportunity to practice my communication skills outside of a clinical or hospital environment! (Female, Occupational Therapy, 2012, ID\#11)

Gain experience in community setting \& build communication skills. (Female, Nutrition and Dietetics, 2013, ID\#50)

There was strong recognition among the students of the need to practice their paediatric communication skills and that the community engagement program gave them the opportunity to build their skills of working with children (Female, Occupational Therapy, 2013, ID\#57), particularly with children from remote or more vulnerable sectors in the community. Their responses included:

To enhance my skills in dealing with children in the outer community. (Male, Physiotherapy, 2013, ID\#61)

Gain more knowledge of the Aboriginal community services for school aged children. (Female, Nursing, 2013, ID\#94)

Staff members also commented on the importance of students practising working with children and the benefit students gained:

Just knowing how to talk to children, which is really our bread and butter when you work in paediatrics. So getting that experience and exposure to chatting to children of different ages, to children of different abilities. ... (Academic Staff Member, ID\#90)

... a lot of students haven't had any experience in terms of interacting with children. ... they're often children of a lower socioeconomic background or Aboriginal children. So again, I think that's important for them to actually be involved in just learning to communicate with them. (Academic Staff Member, ID\#89)

In the survey, 75 per cent of students either 'agreed' or 'strongly agreed' that participation in the community engagement program increased their knowledge about the social determinants of health. In addition to practising professional communication skills, staff members also recognised that students gained generic knowledge about the context in which health care is delivered to specific societal groups. There was a perception that this would make them better health professionals as shown in the following comments:

They'll build better rapport and have a better client-therapist relationship because they'll have a deeper understanding of possibly the needs and the issues around that client. (Academic Staff Member, ID\#80) 
... the whole 'walking a mile in other people's shoes' and trying to understand, particularly for marginalised groups, what their day-to-day experience is, has huge impacts on their expectations of things like health literacy, of compliance, and that understanding of context has to make them better professionals. (Academic Staff Member, ID\#77)

Both staff and students commented on the potential for students to expand some of their profession-specific practice capabilities through the community engagement program:

I think that's one of the unique aspects of some of these community projects, is the sports nutrition side of things. Because most of our students are really interested in sports nutrition, so it's nice that they can go out and do that. (Academic Staff Member, ID\#88)

In some cases students were tutored in specific aspects of professional practice to prepare them to engage in particular activities, thereby ensuring that, as this staff-member commented, the students were not set up to fail:

I like to give them some paediatric tutorials so that they know a bit about fine motor handwriting and hand strengthening in preparation if they're going to do a learning experience with the school students on those areas... (Academic Staff Member, ID\#84)

Students also made reference to the benefits in terms of their profession-specific practice capabilities gained outside their formal placement setting. They commented:

Give students opportunity to practice in their discipline and build skills (Female, Nutrition and Dietetic, 2013, ID\#50)

To expand my skill set and experience. (Female, Speech Pathology, 2013, ID\#11)

It gave me a chance to gain extra experience in areas other than my specific placement. (Female, Occupational Therapy, 2013, ID\#37)

\section{Building confidence and showing motivation}

While many students found community engagement an enjoyable or rewarding experience $(43 \%)$, they also found it broadened their life experience and thus contributed to them becoming more confident in their health professional roles. Therefore, another of the three theme pillars, 'Building Confidence and Showing Motivation', illustrates how, through participation in community engagement activities, with help from UONDRH staff, students gained a feeling of confidence in their ability to handle new or unfamiliar situations.

These activities gave me confidence and real life experience. (Female, Nutrition and Dietetics, 2012, ID\#04)

UONDRH staff helped to come up with and supplement our ideas for activities, which gave the group more confidence to participate. (Male, Physiotherapy, 2013, ID\#61)

Develop rapport and links with people low socio-economic or culturally diverse backgrounds. (Female, Physiotherapy, 2013, ID\#67)

Staff members recognised the progressive development of the students' confidence as they gained more experience in community engagement, commenting that:

You usually find the first couple of times they go out they struggle with that but by the end of their placement when they've been out a few times they're much better at it 
and they can do it more confidently. ... It's something that they learn about managing groups and the group dynamics ... (Academic Staff Member, ID\#88)

So in practice, we are working across agencies all the time. Having the confidence to do that, knowing what that role of the other person is, at what level do you communicate with them at, and how do you tailor what you do to meet their needs. They're getting exposed to that sort of stuff through the after-school learning centre. (Academic Staff Member, ID\#90)

One staff member referred to a particular student who they perceived had grown in confidence as a direct result of practical experiences he had in the community engagement program while on placement. The staff member felt that this experience was potentially transformative and would ultimately lead to him being a better practitioner as seen in the following comment:

He was just a very insulated young fellow that did not have a lot of world knowledge ... [community engagement] changed a lot of his views because of that and I think changed it in a positive way that will actually make him a better clinician because the next time he has to have knowledge of someone, like interact with someone from a rural area or a child that he'll actually be better at that sort of thing. (Academic Staff Member, ID\#80)

Many informants believed that increased confidence and motivation contributed to students improving their employability, so this theme offers the benefit of 'Increasing potential to get a job', as illustrated in Figure 1. This theme has direct relevance to the over-arching key concept of 'Enhancing Work-Readiness and Employability'. It was strongly represented in the data that students knowingly participated in community engagement in order to improve their employment prospects. They were conscious of entering the labour market as a commodity and commented that participation assisted with gaining employment post-graduation (Female, Nutrition and Dietetics, 2011, ID\#30), that it was both an additional challenge and for my CV [curriculum vitae] (Female, Speech Pathology, 2012, ID\#76) or that it enabled them to add another line my CV or resume to aid myself in future employment (Male, Physiotherapy, 2013, ID\#94).

Staff members recognised the potential benefit and encouraged students to demonstrate motivation by becoming involved in the community engagement program:

So, Midnight Basketball, it's a voluntary thing but if you're talking to them and saying, "It looks really good on your resume and it will give you experience and you'll go and you'll have fun and the [other] students are there". It just takes on a different aspect ... [students] give up your Saturday night for a few hours and go and do this. (Academic Staff Member, ID\#88)

... [students' involvement in community engagement] really makes them stand out and we have been very successful in our students obtaining employment at the end of the program. I think it's something when you're looking through $100 \mathrm{CVs}$. The employers are going to pick out something that stands out. (Academic Staff Member, ID\#79).

\section{Better understanding the nature of rural practice}

Exposure to the characteristics of rural practice is important to help build rural health workforce capacity and encourage recruitment and retention of health professionals in regional, rural and remote locations:

So, getting them out there and involved in the community gets the feelings of belonging and being home type of feeling and trying to get the students, especially 
the city students that have never experienced rural before, ... getting them out into the smaller areas ... and seeing how that functions as opposed to a bigger rural community or a city community. (Professional Staff Member, ID\#92)

The last of the theme pillars, 'Better Understanding the Nature of Rural Practice', is about how, through community engagement, students gain an appreciation of the health care needs and priorities of the local community. It thus also relates to developing their knowledge of the social determinants of health, broadening their perspective on how they could contribute to the health and well-being of the community, even outside of the hospital or clinic in which they perform their core health care roles. For example, staff members commented:

... they [students] really get to know the community ... So, rather than people walking through the door and presenting to them as a health professional, they're actually getting to know some of the background. ... So, they actually get to know some of the context for those individuals and families and groups. (Professional Staff Member, ID\#82)

... they will have a much greater understanding of why they are where they are, being able to tailor their treatment and their support much more closely in a way that would allow that person to benefit ... with no understanding of context, they are a person with a problem and they get formularised treatment $A, B$ or $C$, with no understanding of the social 'of health. (Academic Staff Member, ID\#77)

Fifty-one percent of students either 'agreed' or 'strongly agreed' that participation in the community engagement program led them to consider working in a rural location. While the results do not show whether they changed their previous intentions, some students commented that, although they were already inclined to become a rural practitioner, participation reinforces my attitude or I feel more strongly about it now. Students also recognised how participation in the program deepened their understanding of rural health and enhanced their sense of belonging. They responded as follows:

To provide students, particularly those are not from rural areas, with the opportunity to engage with the local community and gain an understanding of the local culture. (Female, Occupational Therapy, 2013, ID\#37)

Help us health students understand some issues faced in the local rural area. (Female, Medicine, 2013, ID\#82)

Encourage future health workers to consider employment in rural areas - engaging in the community promotes feelings of belonging, validation. (Female, Medical Radiation Science, 2011, ID\#58)

Similar to the other two themes, this theme was perceived to have the direct benefit to the students of improving their employment prospects and so links strongly to the core concept of 'Enhancing Work-Readiness and Employability', particular for those students who intended applying for positions in rural locations:

So they're hoping these last few weeks of being involved ... will give them an edge on someone else who comes from a university in the metropolitan area, applying for a job in a rural area but never worked with the community (Professional Staff Member, ID\#78).

Indeed, by the students gaining an improved understanding of rural communities they are perhaps more likely to seek employment in non-metropolitan areas where they perceive they can have a positive influence on the health of the community: 


\begin{abstract}
... a lot of our students of course are from metropolitan areas and haven't engaged in those kinds of activities with people from low socio-economic backgrounds. So that's very important to them so that they can go away and get something out of it but also maybe want to return to the rural areas. (Professional Staff Member, ID\#78)

I see them as opportunities for students to realise and see the community in action and I think that is actually a very attractive part of rural communities. ... I want them to see a bigger picture, which is that embarking on a health career in a rural and regional area, they have an added and really important responsibility to support those in the community that are less able. (Academic Staff Member, ID\#77)
\end{abstract}

In summary, what is for most of the participating students an extra-curricular educational experience in community engagement, serves to hone their professional practice capabilities. It also improves their confidence and provides a platform to explore self-motivation, as well as increasing their understanding of rural health. In the survey, most students reported that they were either 'extremely satisfied' $(35 \%)$ or 'very satisfied' $(52 \%)$ with the community engagement activities and that their participation provided 'very valuable' (42\%) or 'valuable' $(41 \%)$ experience. It is argued that, consequently, they are more work-ready and employable in an increasingly competitive job market, as suggested by this final quotation from a staff member:

I think the whole experience gives them something a bit different which makes them stand out from the crowd and they get extra practical time so they're more competent when they qualify. (Academic Staff Member, ID\#79)

\title{
Discussion
}

This study was initiated because of a perceived internal organisational need to inform decision-making about ongoing sustainability or potential for further development of the community engagement program. The results revealed that the program is indeed a useful strategy that provides health professional students with diversity in applying some of their base knowledge, skills and abilities and broadens their perspectives in a way that is perceived to enhance their work-readiness as future health professionals. Consequently, the program is ongoing, based on the perception that it meets important core aims and priorities of the UONDRH. Further, it provides an alternative, non-traditional platform for students to be proactive in development of their own knowledge and enables them to draw on their community engagement experiences to generate and shape their understanding of what it is to be a health professional. The students' participation in community engagement activities promotes dialogue and opportunities to encounter community members in authentic and diverse contexts that engender humanisation (Freire, 1996), outside of the health care practice setting.

The unique aspect of the UONDRH community engagement program, in comparison with other such programs, is that the UONDRH students' community engagement activities are relatively short and often extracurricular and voluntary. This offers advantages that may be relevant for other undergraduate programs. When on professional placement, students' main priority is the acquisition of profession-specific clinical knowledge, skills and abilities (Qenani et al., 2014; Thompson et al., 2013). While these are essential to their future health professional roles, literature suggests that employers place value on students possessing a broader, more generic skill-set (Caballero \& Walker, 2010; Caballero et al., 2011). This and other previous studies suggest that community engagement targets these generic competencies, as well as adding to their core clinical competencies. With the emphasis heavily focussed on the acquisition of the latter, the challenge for university educators is to create opportunities for students to participate in community engagement and, thus, extend their

Fisher, K., Smith, T., Brown, L., Wakely, L., Little, A., Wakely, K., Hudson, J., \& Squires, K. (2018). Value-adding to health professional student placement experiences: Enhancing work readiness and employability through a rural community engagement program. Journal of Teaching and Learning for Graduate Employability, 9(1), 41-61. 
understanding of their health care role and enhance their employability. Because the UONDRH community engagement program is largely voluntary, students are selective about whether or not they participate, some commenting that time constraints were an inhibitor. While there are some benefits to embedding community engagement in the curricula and making it a priority for students, ultimately to their longer-term benefit, there may be some consequences. One consequence is that it may discourage students from 'life-wide learning' (Thompson et al., 2013).

The work-readiness and employability of new university graduates has been the subject of previous investigations and commentaries in Australia and internationally (Artess, Forbes, \& Ripmeester, 2011; Australia Government Department of Education, 2000; Billett, 2012; Caballero \& Walker, 2010; O'Leary, 2013; Oprean, 2007; Thune, Støren, \& McCracken, 2015; Walker, Storey, Costa, \& Leung, 2015). In acknowledging this issue, in 2015, Universities Australia launched a national strategy focussed on work integrated learning to strengthen collaborations with industry and communities in order to better prepare university graduates for employment (Universities Australia, 2015). While traditional, formal models of university education provide students with many of the pre-requisites for employment in their chosen field, they also need contextually authentic and relevant activities that extend their capabilities (Higgs, 2011) and ensure they are work-ready, improving their chances of obtaining a job when they graduate (Clark et al., 2015; Prout et al., 2014) and meet the expectations of potential employers (Caballero \& Walker, 2010; Caballero et al., 2011; Hager \& Holland, 2006; Walker et al., 2013) in order to develop their broader generic skill set that employers value.

The perceptions of both UONDRH students and staff members in this study is that the community engagement program provides additional opportunities that have the potential to set the students apart from their peers when applying for job. In addition to providing a platform for applying profession-specific capabilities in a variety of situations, it increases their appreciation of the context in which health care is delivered and of the social determinants of health (and illness). Others have made comparable observations about similarly structured, collaborative community engagement initiatives (Deeley, 2014), including the value in promoting students' awareness of local public health issues (Cashman \& Seifer, 2008) and a social justice perspective on the delivery of health care (Marullo \& Edwards, 2000). Such potential outcomes align with prospective employer and community expectations. Health professionals have a much wider responsibility to the community in which they live and work than just providing specific clinical services. This can be particularly true in rural and remote areas, where the health care challenges are greater than in cities (Smith, 2014).

There is a paucity of information about community-engaged learning in rural areas (Jones, McAllister, \& Lyle, 2016b). In countries like Australia that have a geographical misdistribution of health workforce and services (Joyce \& Wolfe, 2005; Mason, 2013), it is essential to encourage students to consider rural or remote practice after graduation. It follows that it is necessary to provide students with positive rural and remote placement experiences. This study has shown the value of a rural community engagement program in immersing students in the local community and exposing them to rural lifestyles. The evidence suggests that the novel experiences of the program, such as working with Indigenous primary school children in small outlying communities, are both enjoyable and rewarding for the students. As a result, they may be more inclined to apply for positions in rural and remote locations. There are many characteristics of rural practice that differ from urban-based practice (Furlong, Clews, \& Randall, 2009; Joyce, McDonald, \& Lawlor-Smith, 2016; McGrail, Humphreys, Joyce, Scott, \& Kalb, 2012) and developing an understanding of these differences is important to help build rural health workforce capacity and encourage recruitment and retention of health professionals in regional, rural and remote locations 


\section{Limitations and strengths}

It is acknowledged that the views of the community partners about the community engagement program are not represented in this study. This may be considered an inadequacy in light of recognised challenges for community engagement in building collaborative relationships (Moore et al., 2016; Weerts \& Sandmann, 2008, 2010). The aim of this study, however, was to investigate the impact of the program as perceived by UONDRH students and staff. There is a further need to examine the impact of this or other community engagement programs from the perspective of community partners and other key stakeholders. With this program ongoing, limited data has been collected from UONDRH community partners under a separate research project; however, staffing changes and funding instability in those organisations has made this difficult. Such variability, which is common in rural and remote areas, results in a need to continually identify new partners and to renegotiate partnership agreements. However, the generalisability of the findings is limited by the fact it is based in one rural region of Australia and on a specific program of community engagement. Further, the response rate of the student survey was low, it having proved difficult to recruit students who had left the region, many of whom had graduated since they participated in the program. Survey responses were also only from students who participated between 2011 and 2013, which has potential to bias perceptions compared to students who participated in later years.

Strengths of this study include that the mixed-method design has permitted triangulation and integration of the perceptions of both staff and students who have been involved in the community engagement program, increasing the validity of the findings (Vaismoradi et al., 2013). It is also based on the perceptions of participants from a wide range of health care disciplines. In spite of the above limitations, the findings add to the evidence that broadening undergraduate health professional curricula using community-engaged learning is beneficial to students and potentially improves their employment prospects. While potentially limiting its transferability to other settings that have different forms of community engagement, this research provides direction for future deliberation in relation to the replication of this model in other settings. Further research is needed to investigate the post-graduate employment outcomes of participating students and whether they secure positions in regional, rural or remote locations. While it was perceived that graduate employability was improved by participation in the UONDRH community engagement program, at this time there is no objective evidence of that outcome. However, an allied health longitudinal graduate outcome study is ongoing (Brown et al., 2017), which may add to the evidence-base.

\section{Conclusions}

It has been argued elsewhere that universities have wider responsibilities to communities than simply producing graduates (Butin, 2010). For higher education institutions to support students in developing capabilities and prepare them for future practice requires engagement with a variety of learning and teaching strategies. Community engagement programs can offer relevant authentic situated 'in context' learning opportunities and foster tangible outcomes for health professional students as they develop knowledge of self and communities in which they may work. These attributes should serve them well in the employment market. The results of this study provide support to the notion that there was value for students in the short-term, community engagement activities, many of which could be readily integrated into existing health professional education programs with considerable benefits. It would also lend itself to other non-health professional programs, such as law, journalism or business studies, as a means of broadening the students' perspectives beyond the limits of their own professional horizons. 


\section{Conflicts of Interest}

The authors declare there are no conflicts of interest.

\section{Source of Funding}

The University of Newcastle, Department of Rural Health (UONDRH) is funded through the Australian Government Department of Health, Rural Health Multidisciplinary Training (RHMT) program. This research received no other specific grants or funding from any external agency. 


\section{References}

Artess, J., Forbes, P., \& Ripmeester, N. (2011). Supporting graduate employability: HEI practice in other countries. Retrieved from:

file://C:/Users/Study/AppData/Local/Temp/2011-Employability-Report-published-byBIS.pdf

Australia Government Department of Education, Trainig and Youth Affairs.(2000). Evaluations and Investigations Programme (EIP). Employer satisfaction with graduate skills: Research report. Canberra: Australian Government. Retrieved from: http://www.voced.edu.au/content/ngv\%3A13863

Australian Government Department of Health (2016). Rural Health Multidisciplinary Training Program. Canberra: Australian Governement. Retrieved from: http://www.health.gov.au/internet/main/publishing.nsf/content/rural-healthmultidisciplinary-training

Australian Institute of Health and Welfare (AlHW). (2014). Australia's Health. Canberra: Australian Government. Retrieved from: https://www.aihw.gov.au/reports/australiashealth/australias-health-2014/contents/table-of-contents

Baum, H. S. (2000). Fantasies and realities in university-community partnerships. Journal of Planning Education and Research, 20(2), 234-246.

Billett, S. (2012). Practice-based learning and professional education: Pursuing quality outcomes and sustainability. In J. Higgs, R. Barnett, S. Billett, M. Hutchings \& F. Trede (Eds.), Practice-based education: Perspectives and strategies (pp. 101-112). Rotterdam, The Netherlands: Sense Publishers.

Blouin, D. D., \& Perry, E. M. (2009). Whom does service learning really serve? Communitybased organizations' perspectives on service learning. Teaching Sociology, 37(2), 120135. doi:10.1177/0092055x0903700201

Boelen, C., \& Woollard, B. (2009). Social accountability and accreditation: A new frontier for educational institutions. Med Education, 43(9), 887-894. doi:10.1111/j.13652923.2009.03413.x

Bringle, R. G., \& Hatcher, J. A. (1996). Implementing service learning in higher education. The Journal of Higher Education, 67(2), 221-239.

Bringle, R. G., \& Hatcher, J. A. (2002). Campus-community partnerships: The terms of engagement. Journal of Social Issues, 58(3), 503-516. doi:10.1111/1540-4560.00273

Brown, L., Smith, T., Wakely, L., Little, A., Wolfgang, R., \& Burrows, J. (2017). Preparing graduates to meet the allied health workforce needs in rural Australia: Short-term outcomes from a longitudinal study. Education Sciences, 7(2), 64.

Butin, D. W. (2010). Service-learning in theory and practice: The future of community engagement in higher education. US: Palgarave McMillan.

Buykx, P., Humphreys, J., Wakerman, J., \& Pashen, D. (2010). Systematic review of effective retention incentives for health workers in rural and remote areas: Towards evidence-based policy. Australian Journal Rural Health, 18(3), 102-109. doi:10.1111/j.1440-1584.2010.01139.x

Caballero, C., \& Walker, A. (2010). Work readiness in graduate recruitment and selection: A review of current assessment methods. Journal of Teaching and Learning for Graduate Employability, 1(1), 13-25.

Caballero, C., Walker, A., \& Fuller-Tyszkiewicz. (2011). The work readiness scale (WRS): developing a measure to assess work readiness in college graduates. Journal of Teaching and Learning for Graduate Employability, 2(2), 41-54. 
Cashman, S. B., \& Seifer, S. D. (2008). Service learning: An integral part of undergraduate public health. American Journal of Preventive Medicine, 35(3), 273-278.

Caspersz, D., \& Olaru, D. (2017). The value of service-learning: The student perspective. Studies in Higher Education, 42(4), 685-700.

Clark, G., Marsden, R., Whyatt, J. D., Thompson, L., \& Walker, M. (2015). 'It's everything else you do...': Alumni views on extracurricular activities and employability. Active Learning in Higher Education, 16(2), 133-147. doi:10.1177/1469787415574050.

Croker, A., Brown, L., Little, A., \& Crowley, E. (2016). Interprofessional relationships for work-integrated learning in healthcare: Identifying scope for ongoing professional development. Creative Education, 7(1), 1729-1738.

Deeley, S. J. (2014). Summative co-assessment: A deep learning approach to enhancing employability skills and attributes. Active Learning in Higher Education, 15(1), 39-51.

Dettwiller, P., Maroney, T., \& Brown, L. (2015). Speaking easy for living and learning: School-based service-learning for speech pathology students. Paper presented at the 13th National Rural Health Conference, Darwin, Northern Territory.

Eklund, E. (2014). Multidisciplinary approach to university community engagement. Australasian Journal of University-Community Engagement, 9(1), 77-99.

Fisher, K., Squires, K., \& Woodley, I. (2016). Community collaboration beyond the red tape. In F. Trede, J. Higgs \& A. Croker (Eds), Collaborating in Healthcare (pp. 211-219): Rotterdan: Sense Publishers.

Friere, P. (1996). Pedagogy of the oppressed (M. B. Ramos, Trans.). London: Penguin.

Furlong, D., Clews, R., \& Randall, W. (2009). From vision to voice: Rural helping as listening to the tales that teach. Atlantic Universities' Teaching Showcase, 29-41.

Furze, J., Black, L., Peck, K., \& Jensen, G. M. (2011). Student perceptions of a community engagement experience: Exploration of reflections on social responsibility and professional formation. Physiotherapy Theory and Practice, 27(6), 411-421.

Hager, P., \& Holland, S. (2006). Graduate attributes, learning and employability. Springer, The Netherlands. Dordrecht: Springer Netherlands.

Hébert, A., \& Hauf, P. (2015). Student learning through service learning: Effects on academic development, civic responsibility, interpersonal skills and practical skills. Active Learning in Higher Education, 16(1), 37-49. doi:doi:10.1177/1469787415573357

Higgs, J. (2011). Practice-based education: A framework for professional education. In the Charles Sturt University The Education for Practice Institute (Ed.). Sydney: Australian Learning and Teaching Council.

Humphreys, J., Wakerman, J., Wells, R., Kuipers, P., Jones, J., \& Entwistle, P. (2008). 'Beyond Workforce": A systemic solution for health service provision in small rural and remote communities. Medical Journal of Australia, 188(8), 77-80.

IBM Corporation. (2013). IBM SPSS Statistics for Windows. Armonk, New York: IBM Corp.

Jones, D., McAllister, L., \& Lyle, D. (2015). Stepping out of the shadows: Allied health student and academic perceptions of the impact of a service-learning experience on student's work-readiness and employability. Journal of Teaching and Learning for Graduate Employability, 6(1), 66-87.

Jones, D., McAllister, L., \& Lyle, D. (2016a). Challenging remote community deficit perspectives: An Australian insight into the role of these communities in the design of their health services and the development of their health workforce. International Journal of Practice-based Learning in Health and Social Care, 4(2), 19-34. 
Jones, D., McAllister, L., \& Lyle, D. (2016b). Community-based service-learning: A rural Australian perspective on student and academic outcomes of participation. The International Journal of Research on Service-Learning and Community Engagement, 4(1), 181-197.

Joyce, C., McDonald, H., \& Lawlor-Smith, L. (2016). General practitioners' perceptions of different practice models:A qualitative study. Australian Journal of Primary Health, 22(5), 388-393.

Joyce, C., \& Wolfe, R. (2005). Geographic distribution of the Australian primary health workforce in 1996 and 2001. Australian and New Zealand Journal of Public Health, 29(2), 129-135. doi:10.1111/j.1467-842X.2005.tb00062.x

Kirby, S., Held, F. P., Jones, D., \& Lyle, D. (2018). Growing health partnerships in rural and remote communities: What drives the joint efforts of primary schools and universities in maintaining service learning partnerships? Primary Health Care Research \& Development, 10 January, 1-15.

Kolb, D. A. (2014). Experiential learning: Experience as the source of learning and development: NJ: Prentice Hall.

Lyle, D., Klineberg, I., Taylor, S., Jolly, N., Fuller, J., \& Canalese, J. (2007). Harnessing a University to address rural health workforce shortages in Australia. Australian Journal of Rural Health, 15(4), 227-233.

Marullo, S., \& Edwards, B. (2000). From charity to justice: The potential of universitycommunity collaboration for social change. American Behavioural Scientist, 43(5), 895912.

Mason, J. (2013). Review of Australian Government health workforce programs. Retrieved from http://www.health.gov.au/internet/main/publishing.nsf/Content/review-australiangovernment-health-workforce-programs

Mathie, A., \& Cunningham, G. (2003). From clients to citizens: Asset-based community development as a strategy for community-driven development. Development in Practice, 13(5), 474-486.

McGrail, M. R., Humphreys, J. S., Joyce, C. M., Scott, A., \& Kalb, G. (2012). How do rural GPs' workloads and work activities differ with community size compared with metropolitan practice? Australian Journal of Primary Health, 18(3), 228-233.

Messum, D., Wilkes, L., \& Jackson, D. (2015). What employability skills are required of new health managers? Asia Pacific Journal of Health Management, 10I(1), 28-35.

Millican, J., \& Bourner, T. (2011). Student-community engagement and the changing role and context of higher education. Education + Training, 53(2/3), 89-99.

Moore, T., McDonald, M., McHugh-Dillon, H., \& West, S. (2016). Community engagement: $A$ strategy for improving outcomes for Australian families. Melbourne: Australian Insitute of Family Studies. Retrieved from: https://aifs.gov.au/cfca/publications/communityengagement

NVivo qualitative data analysis Software. QSR International Pty Ltd, Version 10, 2012.

O'Leary, S. (2013). Collaborations in higher education with employers and their influence on graduate employability: An institutional project. Enhancing Learning in the Social Sciences, 5(1), 37-50.

Oprean, C. (2007). Adequately responding to 'reform' and 'anti-reform' pressures in the Romanian higher education system under the Bologna Process. Higher Education in Europe, 32(1), 91-97. 
Peck, K., Furze, J., Black, L., Flecky, K., \& Nebel, A. (2010). Interprofessional collaboration and social responsibility: Utilizing community engagement to assess faculty and student perception. International Journal of Interdisciplinary Social Sciences, 5(8), 205-222.

Prout, S., Lin, I., Nattabi, B., \& Green, C. (2014). 'I could never have learned this in a lecture': Transformative learning in rural health education. Advances in Health Sciences Education, 19(2), 147-159.

Qenani, E., MacDougall, N., \& Sexton, C. (2014). An empirical study of self-perceived employability: Improving the prospects for student employment success in an uncertain environment. Active Learning in Higher Education, 15(3), 199-213. doi:10.1177/1469787414544875

Rooks, R. N., \& Rael, C. T. (2013). Enhancing curriculum through service learning in the social determinants of health course. Journal of the Scholarship of Teaching and Learning, 13(2), 84-100.

Smith, T. (2014). Health education and practice relationships in a rural context. In J. Higgs, A. Croker, D. Tasker, J. Hummell \& N. Patton (Eds.), Health practice relationships (pp. 161-170). Rotterdam: Sense Publishers.

Stanton, T., Giles Jr, D., \& Cruz, N. (1999). Service-learning: A movement's pioneers reflect on its origins, practice, and future. Michigan Journal of Community Service Learning, 6(1), 133-137.

Thompson, L. J., Clark, G., Walker, M., \& Whyatt, J. D. (2013). 'It's just like an extra string to your bow': Exploring higher education students' perceptions and experiences of extracurricular activity and employability. Active Learning in Higher Education, 14(2), 135-147.

Thune, T., Støren, L. A., \& McCracken, M. (2015). Study and labour market effects of graduate students' interaction with work organisations during education: A cohort study. Education+ Training, 57(7), 702-722.

Australian Collaborative Education Network, Universities Australia, Australian Chamber of Commerce and Industry, Australian Industry Group and the Business Council of Australia (2015). National strategy on work integrated learning in university education. Retrieved from (http://cdn1.acen.edu.au/wp-content/uploads/2015/03/National-WILStrategy-in-universityeducation-032015.pdf)

Vaismoradi, M., Turunen, H., \& Bondas, T. (2013). Content analysis and thematic analysis: Implications for conducting a qualitative descriptive study. Nursing and Health Sciences, 15(3), 398-405. doi:https://dx.doi.org/10.1111/nhs.12048

Wakerman, J., \& Humphreys, J. S. (2012). Sustainable workforce and sustainable health systems for rural and remote Australia. The Medical Journal of Australia, 199(5 Supp.), S14-17.

Walker, A., Storey, K. M., Costa, B. M., \& Leung, R. K. (2015). Refinement and validation of the Work Readiness Scale for graduate nurses. Nursing Outlook, 63(6), 632-638.

Walker, A., Yong, M., Pang, L., Fullarton, C., Costa, B., \& Dunning, T. (2013). Work readiness of graduate health professionals. Nurse Education Today, 33(2), 116-122.

Weerts, D. J., \& Sandmann, L. R. (2008). Building a two-way street: Challenges and opportunities for community engagement at research universities. The Review of Higher Education, 32(1), 73-106.

Weerts, D. J., \& Sandmann, L. R. (2010). Community engagement and boundary-spanning roles at research universities. The Journal of Higher Education, 81(6), 632-657. 